\title{
GESTÃO EM SEGURANÇA PÚBLICA: ANÁLISE DOS FATORES DE VIABILIDADE DA IMPLANTAÇÃO DO CENTRO INTEGRADO DE OPERAÇÕES EM SEGURANÇA PÚBLICA (CIOSP) EM CAICÓ - RN
}

\author{
Flávio Medeiros Lucena ${ }^{1}$ \\ Jorge Peterson Figueiredo ${ }^{2}$
}

\begin{abstract}
RESUMO: O presente trabalho surgiu como proposta em buscar subsídios e fundamentação para expor a necessidade de viabilizar a implantação do Centro Integrado de Operações em Segurança Pública (CIOSP) em Caicó - RN. Para isso, teve como objetivo: indicar os fatores que indicam a necessidade de implantação do Centro Integrado de Operações em Segurança Pública (CIOSP), tendo como eixo indicadores da Polícia Militar do período de 20II a 2013. Desta forma, foi realizada uma pesquisa documental quantitativa no Núcleo de Avaliação e Estatística do Centro de Operações Policiais Militares do $6^{\circ}$ Batalhão de Polícia Militar em Caicó - RN. Os dados analisados (Indicadores Sociais de Criminalidade) pela Polícia Militar indicam aumento da maioria dos índices das ocorrências policiais analisadas, o que ajudaria na viabilidade, implantação e criação do CIOSP por tratar-se de proposta de mudança organizacional na condução do planejamento das ações integradas e interligadas dos órgãos da Segurança Pública contra a criminalidade.
\end{abstract}

Palavras-chave: Criminalidade. Indicadores sociais. Segurança Pública.

\section{INTRODUÇÃO}

O Centro Integrado de Operações em Segurança Pública (CIOSP), é um complexo Sistema de Comunicação de emergências na área da Segurança Pública que está sendo implantado nas Secretarias de Segurança Pública de todo o país com o intuito de agilizar e dinamizar o atendimento dos serviços prestados à sociedade brasileira. É composto de uma unidade de gestão compartilhada, instituída na estrutura organizacional da Secretaria de Estado da Segurança Pública, tendo por finalidade

\footnotetext{
r Bacharel em Administração Pública pela Universidade Federal do Rio Grande do Norte. E-mail: flamlucena@gmail.com.

2 Bacharel em Administração Pública pela Universidade Federal do Rio Grande do Norte. E-mail: jorgepeterson.figueiredo@bol.com.br.
} 
centralizar e aperfeiçoar os serviços de atendimento e despacho de ocorrências de emergências nas respectivas áreas.

O CIOSP funciona ininterruptamente, acolhendo as chamadas aos números de emergências: 190 da Polícia Militar; 193 do Corpo de Bombeiros e 197 da Polícia Civil e ITEP, além do uso de tecnologia de ponta, como, sistema de transmissão de voz e dados, localização automática de veículos, vigilância eletrônica, e geoprocessamento com o uso de mapa digitalizado das áreas abordadas. Todas as tecnologias estão integradas por um sistema informatizado para atendimento ao cidadão e despacho de ocorrências, chamado de Sistema Integrado de operações policiais militares (SIOPM).

O CIOSP possui diversidades operacionais, dentre elas a coordenação das ações de respostas integradas às solicitações emergenciais, colaborando no controle operacional da Polícia Militar, Polícia Civil, ITEP e Corpo de Bombeiros; garantindo que atuem de forma complementar e harmônica, centralizando, integralizando e otimizando as atividades preventivas, repressivas e de socorro à população. Tem como característica intrínseca, a necessidade de dividir o mesmo ambiente físico com as instituições que a compõem, permitindo assim, a gestão compartilhada de meios materiais, humanos e de informações buscando a eficiência e eficácia, além da efetividade das ações de segurança, o que resulta em um melhor atendimento à sociedade.

No Rio Grande do Norte as regiões metropolitanas da Grande Natal e Mossoró, já desfrutam dessa modalidade de serviço público. Entretanto essa modalidade ainda não foi implantada nas áreas populacionais importantes, econômica - política e social; como no caso de Caicó - importante Centro Regional - o que dificulta a uniformidade do atendimento dos serviços de emergência que se relacionam. Porém, já existe um esboço de um Projeto para implantação desta modalidade de serviço idealizado por profissionais da área da segurança pública locais.

As mudanças atualmente em curso na tecnologia da informação requerem cada vez mais dos órgãos de prestação de serviços públicos emergenciais, inovações tecnológicas na prevenção, combate e repressão ao crime organizado. De acordo com 
Ramos, 2013, é visto que através dos tempos o aumento da criminalidade e do tráfico de drogas está cada vez mais migrando para as áreas interioranas dos estados brasileiros. Nessas áreas ocorrem constantes assaltos a bancos, quadrilhas organizadas no tráfico de drogas, grupos de extermínios, falta de perícia especializada para a solução de crimes; e, onde há a inefetividade e ineficiência da prestação dos serviços públicos necessitando de mais atenção por parte das autoridades governamentais (RAMOS, 2013).

Entende-se que é de fundamental importância para a cidade de Caicó a implementação do Centro Integrado de Operações em Segurança Pública (CIOSP) para interligar e integrar os órgãos da área para que busquem ações que possam dar uma resposta rápida e positiva à sociedade no combate ao crime organizado.

\section{2- REFERENCIAL TEÓRICO}

\section{1 - A Ideologia do Planejamento Estratégico}

"Planejamento é a formulação sistemática de estratégias, ações estratégicas e a escolha da melhor ação no momento certo para a organização; quer dizer, é sistemática porque não é pontual, tem início, meio e continuidade" (PEREIRA, 2oII, p. 38). Assim, tem como premissas básicas a coerência e a sustentação em todo o processo organizacional para a obtenção de sucesso diante das mudanças e transformações na organização. Pereira (201I, p.19 apud Mintzberg, Ahlstrand e Lampel et al. 2000), definem a importância do pensamento estratégico para a administração pública como uma ferramenta de evolução ao longo do tempo.

Segundo Misoczky e Guedes (2011, p. 18), "O plano é a expressão de um processo de tomada antecipada de decisões”. Assim, ainda para Misoczky e Guedes (20II, p.18 apud Simon et al. 1970), "é impossível para qualquer indivíduo, por suas limitações cognitivas, avaliar as alternativas de que dispõe e todas as consequências de suas escolhas". Por isso o administrador deve decidir considerando um número limitado de informações que possibilite a identificação dos problemas e algumas situações alternativas. A noção de plano pressupõe um conjunto de idéias tais como 
previsão, organização, coordenação de esforços, acompanhamento e controle das ações, bem como avaliação de resultados. Evoca uma ação reflexiva e intencional de organização de ações e de preparação de instrumentos (programação e orçamento) para alcançar ou produzir um resultado desejado (MISOCZKY E GUEDES, 20II, p. 19).

Desta forma vivencia-se uma mudança radical na condução dos negócios públicos caracterizado pelo sistema gerancialista de onde se extrai termos como o Estado inteligente, o Governo empreendedor, o Estado-empresa. Tal prática norteia tais características para se governar como quem administra uma empresa, já que é por intermédio das entidades públicas, seus órgãos descentralizados que o governo chega até o cidadão.

Para tanto se faz necessário o direcionamento e o desenvolvimento de estratégias para implantação do planejamento estratégico na administração pública.

Segundo Misoczky e Guedes (2011, p. 24 apud Ossorio et al. 2002, p.II7), estratégia pode ser definida como:

[...] um método de pensamento que organiza, a partir da posição particular de percepção de diferentes atores sociais, classificando, hierarquizando e valorizando os dados da realidade - a realidade de cada um - de um modo consciente e calculado com a marca dos interesses e ideologia de cada um, com vista a influir favoravelmente no curso dos acontecimentos.

Assim, a forma de se planejar estrategicamente nas organizações iniciou-se da necessidade de se planejar ações, observando e analisando-se pontos de vista diferenciados, transformando e dando ampla visão sistêmica do ambiente interno e externo, considerando assim, vários outros fatores.

Dessa forma, a estratégia faz com que as organizações identifiquem e entendam quais são os seus pontos fortes e seus pontos fracos com o intuito de alcançar seus objetivos, considerando inclusive as oportunidades e ameaças decorrentes do ambiente.

Conforme Pereira (2011, p. II7 apud Gaj et. al 1986) diz que "Estratégia é uma postura direcionada a procedimentos que devem ser iniciados hoje para se obter, no futuro, o objetivo que se deseja”.

Assim, o planejamento estratégico difunde-se nas organizações como ferramenta usada na definição de estratégias que serão usadas no processo de 
gerenciamento das organizações públicas, traçando objetivos e metas que poderão ser alcançadas ao longo do tempo.

Em conjunto com o pensamento ideológico e estratégico, surgem planos de ações que visam às mudanças necessárias para o melhor desempenho das instituições nos seus diversos produtos e serviços prestados. Dessa maneira, busca-se cada vez mais a inovação no serviço público e no modo como é prestado à sociedade, objetivando-se sempre a excelência e um serviço público de qualidade, contudo, com as constantes mudanças e evoluções tecnológicas, tem-se a tecnologia como a principal aliada nesse processo, através de diversos recursos disponíveis tais como computadores, programas modernos e ainda o avanço no desenvolvimento das chamadas tecnologias da informação e comunicação, as TICs, e não poderia deixar de ser lembrada a rede mundial de computadores a internet que tem facilitado a comunicação em todo o mundo.

O que é bem interpretado por Warschauer (2006, p.47):

[...] pela primeira vez na história da humanidade, as pessoas podem interagir rapidamente e a distância utilizando-se da escrita. Isso lhes possibilita trocar idéias prontamente, enquanto mantém um registro das suas próprias comunicações e uma reflexão sobre ela.

O entendimento da importância da tecnologia e da sua representatividade nas instituições faz com que o elemento tecnológico apresente um diferencial competitivo entre as empresas, sendo visto como estratégia tecnológica e considerado muito importante na formulação das demais estratégias.

De acordo com Cassiolato et al . (1996, p.22)

[...] o conceito de estratégia tecnológica está associado a ações que procuram impulsionar o crescimento da firma atuando sobre o vasto conjunto de tecnologia e sub-tecnologia com as quais ela está envolvida, de maneira a incorporar as mudanças que se reflitam no aumento da competitividade empresarial.

Entretanto, a estratégia tecnológica tem se disseminado também nas instituições públicas, trazendo muitos benefícios para os funcionários e para os usuários dos serviços prestados, o que tem gerado maior agilidade, publicidade e conseqüentemente maior transparência das ações. 
Segundo Pereira e Fonseca (1997, p.65)

[...] a primeira tentativa sistemática de modernização da administração pública brasileira aconteceu na década de 1930, por meio do conhecido esforço do DASP para promover uma reforma administrativa de abrangência e magnitude significativa. Os fundamentos teóricos e operacionais do modelo apregoavam o fortalecimento do poder central com estratégias para melhoria dos padrões vigentes no país e no mundo, naquela ocasião.

Desse modo, não diferente dos demais segmentos institucionais, a segurança pública também se insere no planejamento estratégico e tecnológico, visando sempre o bem estar da população através do combate a criminalidade e ofertar maior e melhor nível de segurança. Contudo investimentos foram feitos ao longo do tempo, e assim adquiridos armas, viatura e equipamentos modernos objetivando o reaparelhamento dos órgãos de segurança, porém precisava-se ainda de algo inovador no tocante a informação, comunicação, monitoramento e distribuição estratégica do policiamento em áreas previamente mapeadas de acordo com o grau de necessidade, tomando por base o número de ocorrências registradas. Nesse contexto, surge o CIOSP, como inovação tecnológica e estratégica no auxílio à redução e combate à criminalidade.

Segundo a definição de Furtado (2002, p.69) o CIOSP é:

[...] espaço físico de forma integrada (ou interligados por intermédio de uma rede de voz e dados de alta velocidade), que pode realizar de forma complementar e harmônica as atividades que configurem o atendimento de emergência, racionalizando o uso dos recursos e obtendo uma maior eficácia neste atendimento.

Para Furtado (2002, p.7o), os principais objetivos do CIOSP são:

a) Promover um canal direto e sempre disponível com o cidadão para que o mesmo possa recorrer às polícias e ao corpo de bombeiros em situação de emergência;

b) Realizar o atendimento ao cidadão com agilidade e presteza;

c) Gerir os recursos disponíveis para realizar o atendimento ao cidadão de forma eficiente, através do compartilhamento de meios materiais, humanos e de informações, para se obter o aperfeiçoamento das atividades policiais preventivas e repressivas;

d) Aumentar o grau de credibilidade da população na polícia, através de um sistema de resposta que se apresente eficiente nos momentos em que a população mais 
precise.

O CIOSP é um centro de operações único, reunindo em instalações com as próprias ferramentas que permitem usar a tecnologia, para solucionar as demandas emergenciais de segurança. (FREITAS, 20II).

Ainda a respeito do CIOSP, segundo Furtado (2002, p.7o)

"[...] esta estrutura centralizada objetiva a gestão compartilhada de meios, materiais e humanos, de informação, buscando-se o aperfeiçoamento das atividades policiais preventivas e repressivas".

Assim, percebe-se a importância e expressividade da ideologia do planejamento estratégico para as instituições, bem como o mérito da tecnologia estratégica e nesse contexto observa-se o que representa o CIOSP para a segurança pública, surgindo como o advento tecnológico e estratégico no combate a criminalidade.

\section{3- METODOLOGIA DA PESQUISA}

O método científico é o caminho, isto é, os artifícios que serão usados para se chegar a um determinado fim (MEDEIROS; MEDEIROS, CARVALHO, 2009).

\section{I Tipo de Pesquisa}

O presente trabalho teve como objetivo, identificar os fatores que indicam a necessidade de implantação do Centro Integrado de Operações em Segurança Pública (CIOSP) em Caicó - RN, tendo como eixo indicadores da Polícia Militar do período de 2011 a 2013. O trabalho usou por base a pesquisa de investigação documental realizada através de indicadores de aumento da criminalidade realizada no Núcleo de Avaliação e Estatística (NAE) do $6^{\circ}$ Batalhão de Polícia Militar do Rio Grande do Norte, localizado em Caicó.

Para Zanella (2006), “a pesquisa de investigação documental é a que envolve a pesquisa de documentos internos ou externos. Para isso, utilizou-se a abordagem quantitativa por tratar-se de dados estatísticos”. 


\subsection{Universo e Amostra}

O Universo da pesquisa compreendeu as áreas de atuação operacional da Polícia Militar em Caicó - RN, divididas em Zonas de atuação, assim sendo: Zona Norte, Zona Oeste, Zona Central e Zona Leste. Essas respectivas zonas são divididas pelas quantidades de bairros existentes em cada área de atuação policial.

A amostra documental foi colhida do período dos anos de 2011 até 2013 , em consulta ao banco de dados do Núcleo de Avaliação e Estatística do $6^{\circ}$ Batalhão de Polícia Militar em Caicó - RN.

Segundo Barbetta (2005, p. 25 apud ZANELLA, 2006, p. 93), "população é o conjunto de elementos que formam o universo e que queremos abranger no nosso estudo. São os elementos para os quais desejamos que as conclusões oriundas da pesquisa sejam válidas”. Já a amostra, deve representar o todo em suas características e suas peculiaridades.

\subsection{Instrumento de Pesquisa}

Foi utilizada a análise documental, pesquisa esta feita através de documentos do banco de dados do Núcleo de Avaliação e Estatística (NAE) do $6^{\circ}$ Batalhão de Polícia Militar em Caicó - RN.

Uma pesquisa pode ser realizada, principalmente, através de questionário, entrevista, observação ou análise documental, entre outros (ZANELLA, 2006).

Assim, a observação é uma técnica que utiliza os sentidos para obter informações da realidade. (ZANELLA, 2006).

Portanto, a pesquisa foi feita pela análise documental com base em relatórios de ocorrências policiais que foram transformados em gráficos com índices variáveis.

\subsection{Coleta de dados}

“A coleta de dados é a etapa da pesquisa em que se dá início à aplicação do instrumento elaborado, com o intuito de se efetuar a coleta dos dados previstos" (MARCONI; LAKATOS, 2007 apud CARVALHO, 2ог, P. 86). 
Para isso, a coleta de dados foi realizada no banco de dados do Núcleo de Avaliação e Estatística (NAE) do $6^{\circ}$ Batalhão de Polícia Militar em Caicó - RN, entre os dias 23 a 27 de setembro de 2013, que envolveu o período compreendido entre os anos de 20II a 2013. Os tipos de ocorrências envolvidas que foram analisadas foram: tráfico de drogas, consumo de entorpecentes, porte ilegal de armas, assalto à mão armada (Roubo), captura de foragidos, furto de veículos, veículos recuperados e homicídios.

\subsection{Tratamento dos dados}

Kerlinger (1980, p. 353 apud ZANELLA, 2006, p. 125) define o processo de análise de dados como a "categorização, ordenação, manipulação e sumarização de dados, que tem por objetivo transformar grandes quantidades de dados brutos em uma forma interpretável e mensurável”.

Os dados foram tabulados e tratados de forma estatística em planilha do aplicativo computacional Excel.

\section{4- ANÁlisE E DISCUSSÃO DOS RESULTADOS}

Ao fazer a análise e discussão dos dados, fez-se necessário embasar e fundamentar essas alterações nos índices das ocorrências citadas mostrando os responsáveis pelas mudanças de aumento e diminuição nas ocorrências valoradas. Essas justificativas estão baseadas no Banco de Dados do Núcleo de Avaliação e Estatística do Centro de Operações Policiais Militares do $6^{\circ}$ Batalhão de Polícia Militar em Caicó - RN, em relatórios de ocorrências policiais e na vivência do dia a dia da operacionalização do serviço ostensivo nas ruas da cidade.

Segundo Barnetta (1998, p. 66 apud ZANELLA, 2006, p. 98), a descrição e apresentação dos dados "compreende a organização dos dados de acordo com as ocorrências dos diferentes resultados observados".

Desta forma, os dados estatísticos fornecidos pelo Núcleo de Avaliação e Estatística (NAE) do $6^{\circ}$ Batalhão de Polícia Militar em Caicó - RN mostraram as variações no número e percentual de ocorrências policiais no período compreendido 
entre os anos de 2011 a 2013, sendo observado e verificado todo o ano de 2011 e 2012, e os seis primeiros meses do ano de 2013, quanto às seguintes criminologias sociais:

No que se refere ao Tráfico de Drogas pode-se verificar que em 201 foram 9 ocorrências; tendo ocorrido um aumento significativo no mesmo período de 2012, para 2I ocorrências, acréscimo de aproximadamente 90\% em relação ao ano anterior; e 07 ocorrências no primeiro semestre de 2013 , diminuição de $66 \%$ em relação a 2012 e de $20 \%$ em relação a 2011 .

De acordo com o que foi observado anteriormente, essa variação nos índices de Tráfico de Drogas, se deu por um aumento e a conseqüente diminuição do número de ocorrências. Entre os primeiros semestres dos anos de 2011 e 2012, houve um aumento significativo do número de ocorrências policiais em decorrência do tráfico de drogas na cidade. Isso se deve à falta de mapeamento geográfico das áreas críticas por parte dos órgãos da Segurança Pública, facilidade dos usuários em adquirir drogas ilícitas, omissão do Poder Público, uma legislação penal ineficiente, falta de integração entre os órgãos da segurança pública, falta de fiscalização eficiente nas fronteiras da cidade (por meio de barreiras policiais itinerantes), etc.

Já a partir do primeiro semestre do ano de 2013, houve um incremento das ações e principalmente, às operações de combate à criminalidade, realizadas entre o serviço de investigação e operacional da Polícia Civil em conjunto com o setor de inteligência $(\mathrm{P}-2)$ e operacional da Polícia Militar; ao patrulhamento ostensivo da Polícia Militar realizado diuturnamente em áreas críticas de consumo; da divisão da cidade em áreas de atuação com policiamento localizado; ação de presença da Polícia nos bairros; informações e denúncias de moradores dos locais afetados; aumento do número de viaturas policiais nas ruas e disque - denúncia por meio do telefone de emergência (190) da Polícia Militar, etc.

No que se refere ao Consumo de Entorpecentes verificou-se que no primeiro semestre de 2011 foram 12 ocorrências de detenções; tendo ocorrido I5 ocorrências em 2012, o que representa um pequeno acréscimo de aproximadamente $25 \%$ em relação ao 
ano anterior (2011); e em 2013, foram 26 ocorrências com um aumento de aproximadamente $26 \%$ em relação a 20I2; e de $117 \%$ em relação a 2011.

Assim, de acordo com o que foi verificado anteriormente durante os primeiros semestres dos anos referidos anos acima, houve um aumento contínuo do número de ocorrências envolvendo o consumo de entorpecentes na cidade. Esse aumento teve respaldo pelos seguintes fatores: legislação penal branda para os consumidores; famílias que na grande maioria das vezes sustentam o vício do filho para não vê-lo praticar outros crimes para comprar a droga para o consumo próprio; aumento dos potenciais consumidores principalmente nas áreas mais abastadas da cidade como a Zona Oeste que compreende os bairros menos favorecidos em infraestrutura urbana, econômica, política e social (Barra Nova, Soledade, João XXIII, Paulo VI, João Paulo II, Walfredo Gurgel, Frei Damião, Casas Populares e Adjuto Dias; ao número de albergados e familiares (com desvios de conduta) que transferem moradia para a cidade em virtude de apenados cumprindo os regimes de pena criminal fechado, semiaberto e aberto na Penitenciaria Estadual do Seridó (PES), mais conhecida popularmente como Pereirão. Ainda há outro fator preponderante para o crescimento do consumo de entorpecentes na cidade de Caicó - RN que é rota de passagem de pessoas; servindo de ligação entre o Estado vizinho da Paraíba, a Região Leste do Estado do Ceará e a Zona Oeste do Estado do RN. Também nota-se a facilidade com que a droga é comprada em pontos chamados bocas de fumo, que são locais na grande maioria das vezes não investigados pela Polícia Civil, por falta de efetivo funcional, falta de equipamentos de uso pessoal e viaturas e/ou realocação de pessoal.

No que se refere ao Porte Ilegal de Armas pode-se verificar que em 2or foram 04 ocorrências de apreensão de arma de fogo; em 2012 foram io ocorrências, o que representou um aumento exorbitante de $150 \%$ em relação a 2011 ; já em 2013 foram I9 ocorrências, o que representou um aumento de 275 \% em relação a 2011 ; e um aumento de $90 \%$ em relação a 2012.

Então, observa-se que entre os primeiros semestres dos anos de $2011,2012 \mathrm{e}$ 2013, houve um aumento significativo no número de ocorrências por porte ilegal de 
armas. Alguns fatores contribuíram para essa marca, tais como: ações de patrulhamento constante com realização de abordagens, ação presença da Polícia Militar, monitoramento via NAE - COPOM com mapas sobre áreas críticas de assaltos e tráfico de drogas, denúncias da população pelo disque-denuncia da Polícia Militar, fiscalização conjunta das fronteiras estaduais entre a Polícia Militar, Polícia Rodoviária Estadual e Polícia Civil com a Operação Divisa Segura; interceptação feita pelo Serviço de investigação da Polícia Civil na aquisição dessas armas pelos criminosos; barreiras policiais itinerantes em toda a cidade; aumento do efetivo policial em períodos de grande fluxo de pessoas e veículos na cidade (como Carnaval e Festa de Santana), etc.

No que se refere a assalto à mão armada (Roubo) verificou-se que zor foram 18 ocorrências; em 2012 foram 63 ocorrências, o que representa um acréscimo exagerado de 250\% em relação ao ano anterior; já em 2013 foram 40 ocorrências, o que representa uma diminuição de aproximadamente $58 \%$ em relação ao ano de 2012, e de um aumento considerável de $125 \%$ em relação ao ano de 2011 .

Desta forma, verificou-se que entre os primeiros semestres dos anos de 2011 e 2012 houve um acréscimo no número de ocorrências de assalto à mão armada ocasionado pela falta de policiamento em horários de refeições em locais comerciais específicos; ligações de trote para o 190 com a finalidade de retirar o policiamento ostensivo das áreas comerciais; falta de estrutura logística (viaturas quebradas e pessoal) para realização de abordagens e ação de presença, etc. Esse aumento se deve a necessidade de dinheiro para a compra de drogas pelos usuários; pelo aumento da quantidade e circulação do dinheiro na cidade proveniente do comércio e do fluxo de pessoas transitando na cidade em feriados e datas comemorativas; e da facilidade da prática de assaltos em áreas marginais da cidade com policiamento insuficiente.

Já essa redução no número de ocorrências no primeiro semestre de 2013, se deve a prática orientada pelo Comando do policiamento na realização de abordagens policiais no centro da cidade e área comercial; operações e fiscalizações de trânsito itinerantes em áreas críticas e de fronteiras entre os Estados (Operação Divisa Segura 
2013); serviço ostensivo de viaturas policiais com rondas pelos bairros afastados, denúncias feitas pela população através do telefone 190 da Polícia Militar, etc.

No que se refere à captura de foragidos pode-se verificar que em 201 foram 04 ocorrências; em 2012 foram II, o que representa um aumento de aproximadamente $180 \%$ em relação ao ano anterior; se mantendo nesse patamar em 2013; o que representa igualdade em relação ao ano de 2012.

Com os índices acima, observa-se que houve um aumento do número de ocorrências envolvendo a captura de foragido da justiça entre os primeiros semestres de 20Ire 2012, se mantendo estável no primeiro semestre de 2013. Isso se deve às abordagens policiais rotineiras a suspeitos; regresso de presos dos grandes centros urbanos com familiares na cidade (migração do crime), rota de fugas alternativas, bonificação por captura (Folga operacional em um dia); patrulhamento ostensivo 24 horas realizado pela Polícia Militar, praticando assim abordagens a suspeitos e procurando identificá-los; e também pela Gestão Participativa da população que através de denúncias anônimas delatam pessoas em atitudes suspeitas. O sistema carcerário do RN vem passando nos últimos anos por um processo de falência das instituições no que tange a alimentação, condições de higiene, saúde, habitação, etc. Isso de certa forma favorece a fuga de detentos de Presídios e centros de detenção provisória o que é muito comum atualmente.

No que se refere a Furto de Veículos verificou-se que em 201 foram 02 ocorrências; em 2012 foram 02 ocorrências, o que representa o mesmo valor percentual em relação ao ano anterior; já em 2013 foram 09 ocorrências, o que representa um aumento extravagante de 350\%em relação aos anos de 2011 e 2012.

Nota-se que houve uma estabilidade no número de ocorrências de furto de veículos entre os primeiros semestres dos anos de 20Ir e 2012. Isso se deve a uma fiscalização realizada pelo Departamento Estadual de Trânsito; denúncias de carros em atitudes suspeitas feitas pela população pelo telefone 190; averiguação e consulta de placas de veículos feitas pela Polícia Militar através do site do Detran Net e da Rede Infoseg, etc. 
Já no primeiro semestre de 2013, houve um aumento no número de furtos de veículos que pode ser verificado através de: estruturação logística e operacional dos bandidos e quadrilhas com o intuito de praticar assaltos a casas lotéricas, correios e bancos; que migraram de regiões para regiões ou até mesmo de Estado para Estado em busca de maiores facilidades para obter dinheiro para financiar o tráfico de armas e drogas. Esse indicador está diretamente relacionado com o aumento do número de veículos recuperados, pois são diretamente proporcionais, mas nem sempre com êxito o fato de ser furtado um veículo, ele deva ser encontrado. Mas, com o trabalho realizado pela Polícia Militar de Caicó - RN, através de denúncias da população e de respostas rápidas quanto à identificação e recuperação destes veículos, pode-se obter êxito nestes tipos de ocorrências.

No que se refere ao número de veículos recuperados pode-se verificar que em 201 foram ol ocorrências; em 2012 foram 02 ocorrências, o que representa um acréscimo de aproximadamente I00\% em relação ao ano anterior; já em 2013 foram 04 ocorrências, o que representa um aumento de I0o\% em relação ao ano de 20I2, e de um acréscimo de $300 \%$ em relação ao ano de 2011 .

Observa-se que houve um acréscimo nas ocorrências envolvendo veículos recuperados entre os primeiros semestres dos anos de 2011, 2012 e 2013. Pode-se observar a relação direta entre os furtos e os veículos recuperados. Isso se deve às denúncias de veículos abandonados pela população ao telefone de emergência da Polícia Militar (19o); ao trabalho de investigação e localização da Polícia Civil, a perseguição e persistência da Polícia Militar em localizar e prender os bandidos; a Rede Infoseg e o DETRANNET de averiguação e localização de pessoas e veículos, etc.

No que se refere ao número de Homicídio (por arma de fogo) verificou-se que em 2011 foram 05 ocorrências; em 2012 foram o9 ocorrências, o que representa um aumento de aproximadamente 80\% em relação ao ano anterior; já em 2013 foram 02 ocorrências, o que representa uma diminuição de aproximadamente $350 \%$ em relação ao ano de 2012, e de uma diminuição de $150 \%$ em relação ao ano de 2011 . 
Então, tem-se verificado um aumento do número de ocorrências de Homicídio entre os primeiros semestres dos anos de 20II e 2012. Isso se deve falta da fiscalização e ostensividade do serviço operacional da Polícia Militar nas ruas; deficiência de efetivo de policiais nas ruas (áreas comerciais), legislação penal branda oferecendo margem a prática criminal; aumento do número de armas circulando pelas fronteiras estaduais circunvizinhas; carência de abordagens em áreas críticas de assaltos e consumo de drogas, dívida de drogas, acerto de contas entre traficantes, vingança, rixa familiar, latrocínio (Roubo seguido de morte), crime encomendado, Pistolagem, etc. No entanto, esses fatos são investigados pela Polícia Civil e muitos dos quais não são desvendados por falta de uma equipe de perícia no ITEP da cidade.

Já em 2013, houve uma diminuição no número de homicídios pela criação de novas modalidades de policiamento, ações conjuntas entre as diversas modalidades de policiamento com realização de abordagens constantes, etc.

Então, diante do que foi verificado nos indicadores sociais de criminalidade e ao fazer uma análise conjunta entre essas variantes na cidade de Caicó - RN foi obtida uma diminuição nos índices: tráficos de drogas, Roubo e Homicídio. Isso se deu em suma pela ostensividade do serviço policial e de algumas ações realizadas entre a Polícia Militar, Polícia Rodoviária Estadual e Polícia Civil, mesmo com toda a precariedade dos recursos logísticos da área. Já os índices que aumentaram foram: consumo de entorpecentes, porte ilegal de armas, captura de foragido, furtos de veículos e veículos recuperados. É observado que as ações entre os órgãos acontecem de forma desordenada sem uma coordenação geral de planejamento de ações e informações.

Desta forma, deveria haver uma integração e interligação entre os órgãos que compõem a área da Segurança Pública com o objetivo de minimizar os efeitos dos condicionantes criminais que evoluíram e que assolam a população, buscando promover a melhoria no atendimento de excelência a sociedade.

Assim, o Centro Integrado em Segurança Pública atuaria como promotor dessa melhoria, oferecendo serviços de qualidade aos diversos órgãos da área tais como: 
Central de monitoramento por câmeras de áreas críticas e comerciais; mapa de localização de viaturas por GPS, integração dos órgãos com serviço de atendimento e despacho de ocorrências; Estrutura logística e de equipamentos, e Equipe de perícia em medicina legal, Integração e interligação entre os órgãos, etc.

\section{CONSIDERAÇÕES FINAIS}

Então diante dos indicadores sociais de criminalidade referenciados na pesquisa os quais foram verificados pela Polícia Militar nos primeiros semestres dos anos de 2011, 2012 e 2013; observou-se que foi identificado que o número de ocorrências referentes ao tráfico de drogas e o número de detenções realizadas por consumo de entorpecentes foi de $20 \%$ e $117 \%$, havendo uma redução significativa no tráfico de drogas e um aumento exorbitante nas detenções pelo consumo de entorpecentes. Esses indicadores referenciam o incremento das ações e principalmente, ás operações policiais de combate à criminalidade, realizadas entre o serviço de investigação $(\mathrm{P}-2)$ e o setor de inteligência da Polícia Civil; ao patrulhamento ostensivo da Polícia Militar realizado diuturnamente em áreas críticas de tráfico de drogas; ao esforço conjunto dos órgãos da segurança pública da cidade em combater efetivamente o tráfico nas periferias, mesmo, não dispondo de viaturas e meios adequados ao enfrentamento mais a coragem em desarticular os fornecedores locais, a bonificação por quantidade de droga apreendida (Folga operacional em um dia), da divisão da cidade em áreas de atuação com policiamento localizado; ação de presença da Polícia nos bairros; informações e denúncias de moradores dos locais afetados; aumento do número de viaturas policiais nas ruas e disque - denúncia por meio do telefone de emergência (190) da Polícia Militar, etc.

Nas ocorrências de detenções referentes ao porte ilegal de armas o índice verificado foi de $275 \%$, havendo um aumento na quantidade de armas apreendidas, reduzindo esse índice social de criminalidade, devido principalmente às ações de patrulhamento constante com realização de abordagens, ação presença da Polícia Militar, monitoramento via NAE - COPOM com mapas sobre áreas críticas de 
assaltos e tráfico de drogas, denúncias da população pelo disque-denuncia da Polícia Militar, etc.

Quanto ao número de ocorrências relacionadas a assalto a mão armada (Roubo), observou-se que foi identificado o índice de $58 \%$, havendo uma redução nessa prática criminosa, que foi verificada pela prática orientada pelo Comando do policiamento na realização de abordagens policiais no centro da cidade e área comercial; operações e fiscalizações de trânsito itinerantes em áreas críticas e de fronteiras entre os Estados (Operação Divisa Segura 2013); serviço ostensivo de viaturas policiais com rondas pelos bairros afastados, etc.

Nas ocorrências de detenções referentes à captura de foragido, observou-se que foi identificado o índice de $180 \%$, havendo aumento significativo nessa modalidade criminosa, que foi verificado a uma maior fiscalização do Sistema Penitenciário solicitando transferências de presos que possam incitar motins e rebeliões com o intuito de fuga; Denúncias de pessoas em atitude suspeita; fiscalização e averiguação de carros suspeitos; sistema de consulta de pessoas pela Rede Infoseg; ampla divulgação através das redes sociais na internet de pessoas fugitivas e que praticaram atos ilícitos (crimes e delitos), etc.

Nas ocorrências de detenções referentes furto de veículos e nas ocorrências referentes ao número de veículos recuperados, observou-se que foi identificado o índice de $350 \%$ e $300 \%$, ou seja, houve um aumento da prática criminosa de furtos de veículos que foi compensado pelo aumento na quantidade de veículos recuperados, havendo no geral uma redução nas práticas criminosas, evidenciado pela estruturação logística e operacional dos bandidos e quadrilhas com o intuito de praticar assaltos a casas lotéricas, correios e bancos; que migraram de regiões para regiões ou até mesmo de Estado para Estado em busca de maiores facilidades para obter dinheiro para financiar o tráfico de armas e drogas. Esse indicador está diretamente relacionado com o aumento do número de veículos recuperados, pois são diretamente proporcionais, mas nem sempre com êxito o fato de o ser furtado um veículo, ele deva ser encontrado. E pelas denúncias de veículos abandonados pela população ao telefone de emergência 
da Polícia Militar (19o); ao trabalho de investigação e localização da Polícia Civil, a perseguição e persistência da Polícia Militar em localizar e prender os bandidos; a Rede Infoseg e o DETRANNET de averiguação e localização de pessoas e veículos, etc.

Nas ocorrências de detenções referentes a homicídios, observou-se que foi identificado o índice de $150 \%$, ou seja, houve uma redução significativa, nessa prática criminosa, pelo fato do aumento da fiscalização e ostensividade do serviço operacional da Polícia Militar nas ruas; aumento do número de policiais nas áreas comerciais, número maior de viatura nas áreas e zonas de atuação policial da cidade, criação de novas modalidades de policiamento, etc.

Os dados analisados (indicadores sociais de criminalidade) pela Polícia Militar indicam aumento na maioria dos índices das ocorrências policiais analisadas. Tal fato ajudaria no projeto de viabilidade e criação do CIOSP por tratar-se de proposta de mudança organizacional na condução do planejamento das ações integradas e interligadas dos órgãos da Segurança Pública contra a criminalidade. Desta forma, a implantação de tal empreendimento, seria um marco diferencial para as organizações da área da segurança no combate à criminalidade, incidindo positivamente nas ações e metas de diminuição dos indicadores sociais da criminalidade como recurso de adaptação às mudanças informacionais no mundo globalizado.

Desta forma, existem dúvidas quanto à aquisição de recursos para a implantação, ao gerenciamento do centro, à localização estratégica ideal, etc. No entanto, existem outros CIOSPs implantados no Estado do RN e no Brasil, já em operação, que servirão de fonte para sugestões e informações, e que vão poder balizar o projeto. Como sugestões pode-se observar os convênios entre os Governos Federal, Estadual e Municipal para aquisição de recursos, a gestão compartilhada dos CIOSPs, e (localização) Centro Integrado de Comando e Controle Móvel (CICCM). Desta forma, baseadas em estudos na área surgirão novas pesquisas, debates e estudos que ampliarão o leque de possibilidades a respeito desta problemática com o objetivo de referenciar mais teorias e práticas em outras localidades. 
Contudo, conclui-se que ficou evidenciada a veracidade e relevância das informações e dos documentos necessários à realização de tal pesquisa. De tal forma que, as informações repassadas nos dão a noção da grandiosidade do tema, mostrando as deficiências e dificuldades da Segurança Pública para a implantação do projeto na cidade.

\section{REFERÊNCIAS}

CARVALHO, Maria Luíza Azevedo de. Fatores que afetam a intenção em continuar o uso do e-learning: um estudo com professores de cursos de graduação à distância da UFRN. 20I0. I8I p. Monografia (Graduação em Administração) - Departamento de Ciências Administrativas da UFRN, Natal, 2010.

CASSIOLATO, José Eduardo et al . A relação universidade e instituição de pesquisa com setor industrial: uma análise de seus condicionantes. Rio de Janeiro: IE/UFRJ, 1996.

FREITAS, Francisco Tércio de. A gestão da informação na área de segurança pública: gerenciamento eletrônico dos documentos e segurança da informação do Centro Integrado de Operações de Segurança Pública _ CIOSP_RN. Monografia (Graduação Biblioteconomia) UFRN, Natal, RN 201 .

FURTADO, Vasco. Tecnologia e Gestão da Informação na Segurança Pública. Editora Garamond Ltda, Rio de janeiro 2002.

GURGEL, André Morais. Estágio Supersivionado III. Plataforma Virtual de Ensino Aprendizagem. Sedis. UFRN, 2013. Disponível em: http://mdl.sedis.ufrn.br/moodle/course/view.php?id=89> Acesso em I8 Abr. 2013. GURGEL, André Morais. Estágio Supervisionado IV. Manual Oficial de Apresentação do TCC. Plataforma Virtual de Ensino Aprendizagem. Sedis. UFRN, 2013. Disponível em: http://mdl.sedis.ufrn.br/moodle/course/view.php?id=332>. Acesso em 24 Set. 2013. 
MANGABEIRA, Heronides. Blog do Cabo Heronides Mangabeira. Disponível em: http://heronidesmangabeira.com/?p=2463> Acesso em 29 Set. 2013.

MARIA, Jota. Blogspot. 2008. Disponível em: http://jotamariacopom.blogspot.com.br/> Acesso em 12 Mar. 2013.

MATO GROSSO. SESED. Secretaria de Estado de Segurança Pública. 2013. Disponível em: http://www.seguranca.mt.gov.br/ciosp.php?IDCategoria=97. Acesso em I8 Abr. 2013.

MEDEIROS, João Bosco de. (Coord.); MEDEIROS, Rildeci (Coord.); CARVALHO, Maria Regina de S (Org.). Estrutura do trabalho científico: padronização e abordagem crítica. Natal: EDUFRN, 2009.

MEDEIROS, Maria da Penha Machado et al. Orientações e normas para a elaboração e apresentação de relatórios científicos e monografias. Natal: [s.n.], 2004.

PEREIRA, Maria José Lara de Bretas; FONSECA, Gabriel Marques. Faces da decisão: as mudanças de paradigmas e o poder da decisão. São Paulo: Makron books, 1997.

PEREIRA, Maurício Fernandes. Administração Estratégica / Maurício Fernandes Pereira. - Florianópolis: Departamento de Ciências da Administração / UFSC; [Brasília]: CAPES: UAB, 2011.

PINTO, Miriam de Magdala. Tecnologia e Inovação. 2. Ed. reimp - Florianópolis: Departamento de Ciências da Administração / UFSC; [Brasília]: CAPES: UAB, 2012.

RAMOS, Silvia. Centro de Estudos de Segurança e Cidadania (CESeC): Aumenta número de crimes em cidades do interior brasileiro. 20II. Disponível em: 
http://wwwi.folha.uol.com.br/cotidiano/881548-aumenta-numero-de-crimes-emcidades-do-interior-brasileiro.shtml. Acesso em I8 Abr. 2013.

RIO GRANDE DO NORTE. $6^{\circ}$ Batalhão de Polícia Militar. COPOM. Núcleo de Avaliação e Estatística. Banco de Dados.> Acesso em I2 Set. 2013.

RIO GRANDE DO NORTE. Polícia Militar. Centro Integrado de Operações em Segurança Pública (CIOSP). Mossoró, RN. Disponível em: http://tribuna.mobi/noticia/governo-implanta-sistema-de-monitoramento-nooeste/I4195I>. Acesso em I2 Mar. 2013.

\section{RIO GRANDE DO NORTE. SEARH. Secretaria de Estado da Administração e} Recursos Humanos. Escola de Governo. 2013. Disponível em: http://www.der.rn.gov.br/content/aplicacao/searh escola/imprensa/enviados $/$ noticiadetalhe asp? Imprensa $=0$ \&ncodigonoticia $=3248 \mathrm{I}>$. Acesso em I2 Mar. 2013.

\section{RIO GRANDE DO NORTE. SESED. Secretaria de Estado da Segurança Pública e} da Defesa Social. 2013. Disponível em: http://www.defesasocial.rn.gov.br/contentproducao/aplicacao/sesed/principal/envi ados/index.asp>. Acesso em 18 Abr. 2013.

SILVA, Janílson Cézar de Araújo. Mini Projeto de Transição COPOM / CIOSP. $6^{\circ}$ Batalhão de Polícia Militar do Estado do Rio Grande do Norte. Março de 2012.

SOARES, Luiz Eduardo. Segurança Pública: Passado, Presente e Futuro. Estudos Avançados 20 (56). Universidade Cândido Mendes, RJ, 2006.

VERGARA, Sylvia Constant. Projetos e Relatórios de Pesquisa em Administração. Estágio Supervisionado III. Plataforma virtual de ensino aprendizagem. Sedis. 
UFRN. Disponível em: http://mdl.sedis.ufrn.br/moodle/course/view.php?id=89>. Acesso em o8 de Maio. 2013.

ZANELLA, Liane Carly Hermes. Metodologia da pesquisa. Florianópolis: SEaD/UFSC, 2006.129 p. Disponível em: http://www.sedis.ufrn.br/mdlacademico/mod/resource/view.php?id=997I $>$. Acesso em i9 jul. 2010.

WARSCHAUER, Mark. Tecnologia e inclusão social: a exclusão digital em debate. São Paulo: Editora Senac, 2006. 